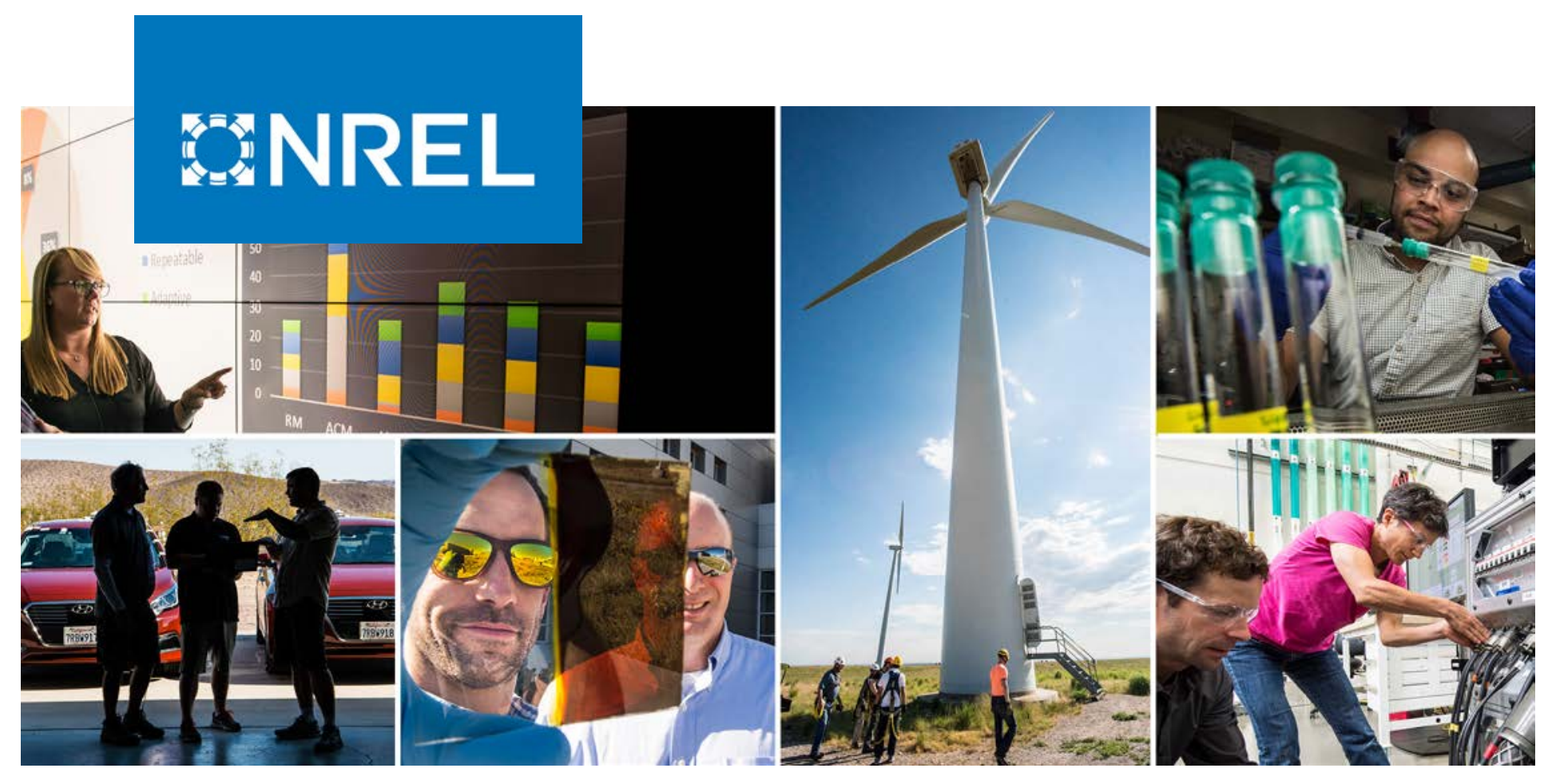

\title{
Rapid Development of Disruptive Photovoltaic Technologies
}

Andriy Zakutayev

National Renewable Energy Laboratory

NREL is a national laboratory of the U.S. Department of Energy

Office of Energy Efficiency \& Renewable Energy

Operated by the Alliance for Sustainable Energy, LLC

This report is available at no cost from the National Renewable Energy Laboratory (NREL) at www.nrel.gov/publications.

\section{Technical Report}

NREL/TP-5K00-73041

January 2019 


\title{
GHREL
}

\section{Rapid Development of Disruptive Photovoltaic Technologies}

\author{
Andriy Zakutayev \\ National Renewable Energy Laboratory
}

\section{Suggested Citation}

Zakutayev, Andriy. 2019. Rapid Development of Disruptive Photovoltaic Technologies. Golden, CO: National Renewable Energy Laboratory. NREL/TP-5K00-73041.

https://www.nrel.gov/docs/fy19osti/73041.pdf.

NREL is a national laboratory of the U.S. Department of Energy Office of Energy Efficiency \& Renewable Energy Operated by the Alliance for Sustainable Energy, LLC

This report is available at no cost from the National Renewable Energy Laboratory (NREL) at www.nrel.gov/publications.

Contract No. DE-AC36-08GO28308
Technical Report NREL/TP-5K00-73041 January 2019

National Renewable Energy Laboratory 15013 Denver West Parkway Golden, CO 80401

303-275-3000 • www.nrel.gov 


\section{NOTICE}

This work was authored by the National Renewable Energy Laboratory, operated by Alliance for Sustainable Energy, LLC, for the U.S. Department of Energy (DOE) under Contract No. DE-AC36-08G028308. Funding provided by U.S. Department of Energy Office of Energy Efficiency and Renewable Energy Solar Energy Technologies Office. The views expressed herein do not necessarily represent the views of the DOE or the U.S. Government.

This report is available at no cost from the National Renewable Energy Laboratory (NREL) at www.nrel.gov/publications.

U.S. Department of Energy (DOE) reports produced after 1991 and a growing number of pre-1991 documents are available free via www.OSTI.gov.

Cover Photos by Dennis Schroeder: (clockwise, left to right) NREL 51934, NREL 45897, NREL 42160, NREL 45891, NREL 48097, NREL 46526.

NREL prints on paper that contains recycled content. 


$\begin{array}{ll}\text { Project Period: } & \text { 1 Oct 2015 - 30 Sept } 2018 \\ \text { Project Budget: } & \$ 1,660,000 \\ \text { Submission Date: } & 28 \text { September 2018 } \\ \text { Recipient: } & \text { National Renewable Energy Laboratory } \\ \text { Address: } & 15013 \text { Denver West Pkwy, Golden, CO } 80401 \\ \text { Agreement Number: } & \text { SuNLaMP 30302 } \\ \text { Awarding Agency: } & \text { DOE EERE SETO PV subprogram } \\ \text { Working Partners: } & \text { Colorado School of Mines } \\ \text { Principal Investigator: } & \text { Andriy Zakutayev } \\ & \text { Scientist } \\ & \text { Phone: 303-384-6467 } \\ & \text { Email: andriy.zakutayev@nrel.gov }\end{array}$




\section{Executive Summary}

Development of new PV technologies based on novel materials is an important direction of solar cell research to enhance the odds for beyond-TW scaling of solar energy production. However, such research presents a significant technical challenge, because it requires a balance between sufficient breadth (screening new materials) and depth (development of PV devices) of the problem. The objective of this project was to establish novel inorganic photovoltaic absorbers using rapid development approach. The studied materials were the potentially scalable defecttolerant oxide- and nitride solar cell absorbers. For one of these materials $\left(\mathrm{ZnSnN}_{2}\right)$, we have experimentally demonstrated how to achieve low carrier density required for solar cell fabrication, and demonstrated that this synthesis process leads to near band edge photoluminescence supporting high optoelectronic quality of the material. For this $\mathrm{ZnSnN}_{2}$ material, we also showed that cation disorder does not significantly influence carrier transport, and that benign defect complexes can lead to improved doping control, both supporting the targeted defect tolerance of this material. All these results have been summarized in peer review publications, some featured on journal covers. In addition, we established a new class of antiperovskite absorbers, and published several review articles of the field.

\section{Background}

Development of new PV technologies based on novel materials could create a new industry with independent supply chains, foster market diversification, and attenuate market volatility. All these factors can enhance the odds for beyond-TW scaling of solar energy production. Such disruptive PV technologies must be competitive with current technologies in efficiency, cost, and reliability, and they should use readily available elements. In addition, they also have to be compatible with low-capex production processes to ensure rapid industry growth after initial commercialization.

Developing new PV absorber technologies is a significant technical challenge, because it requires a balance between sufficient breadth (screening new materials) and depth (development of PV devices) of research. These technical hurdles are addressed by the complementary use of computational materials science and experimental synthesis/characterization techniques, both part of the Rapid Development approach. With this approach, the project can span the entire PV development cycle, from materials exploration, through targeted research on individual materials, to device integration. ${ }^{1}$

One class of emerging PV absorbers studied in literature have some resemblance to existing PV technologies and reported measurable efficiencies. Examples of such emerging PV absorber materials discussed below include binary chalcogenides related to $\mathrm{CdTe}$ (e.g., $\mathrm{SnS}^{2}, \mathrm{Sb}_{2} \mathrm{Se}_{3}{ }^{3}$ ), copper chalcogenides related to CIGS (e.g., $\mathrm{Cu}_{2} \mathrm{SnS}_{3},{ }^{4} \mathrm{CuSbSe}_{2}{ }^{5}$ ), and emerging absorber materials related to MAPI. These absorbers have been recently reviewed as a part of this project. $^{6}$

The other class is the emerging PV absorbers for which high-performing prototype solar cells have not been reported. One example is emerging PV technologies that feature new absorber physics, including multiple exciton generation, ${ }^{7}$ hot-carrier extraction, ${ }^{8}$ ferroelectric photovoltaics, ${ }^{9}$ and so on. Another example includes new absorber chemistries with conventional 
absorber physics, such as oxides, ${ }^{10}$ nitrides, ${ }^{1112}$ and mixed-anion compounds. This last group is in the focus of this project.

\section{Introduction}

The goal of this project was to develop defect-tolerant oxide- and nitride absorbers for photovoltaic solar cells technologies, that can be manufactured using commercial sputtering equipment common for the flat-panel-display or architectural-glass-coating industries. The defect-tolerant absorber materials in focus of this project were $\mathrm{ZnSnN}_{2}$ compounds and ( $\left.\mathrm{Sn}, \mathrm{Zn}\right) \mathrm{O}$ alloys, as well as emerging antiperovskite and wurtzite $\mathrm{Mg}-\mathrm{Sb}-\mathrm{N}$ materials. These novel absorbers are turned into PV technologies using the Rapid Development approach that combines high-throughput experimentation and high-accuracy calculations, demonstrated in the past on the example of novel $\mathrm{Cu}_{2} \mathrm{SnS}_{3}$ absorbers ${ }^{4}$ and $\mathrm{CuSbS}_{2}$ solar cells ${ }^{5}$.

The project consisted of three periods, with two tasks, two progress indicators, and one milestone per period (on average). In the first period, we performed research to down-select from two to one absorber candidates. In the second period, the project focused on improving the optoelectronic quality of the selected absorber, with additional tasks on technoeconomic analysis, and on theoretical exploration of the next-generation of absorbers. In the third period, we worked towards establishing a photoresponse from the absorbers, and synthesizing the most promising next-generation absorber materials identified by theory.

\section{Project Results and Discussion}

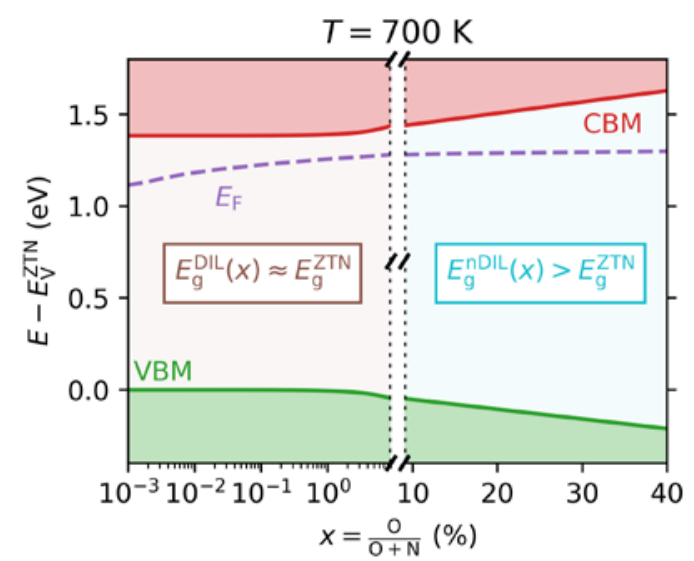

Fig. 1. ZnSnN2 electronic structure and doping as a function of $\mathrm{O}$ and $\mathrm{Zn}$ content
Doping control is necessary to unlock the technological potential of the $\mathrm{ZnSnN}_{2}(\mathrm{ZTN})$ semiconductors. It has been demonstrated experimentally that a reduction of the carrier densities towards semiconducting nondegenerate level below $10^{17} \mathrm{~cm}^{-3}$ can be achieved in oxygen-containing and $\mathrm{Zn}$-rich ZTN samples. This is theoretically unexpected, because $\mathrm{Znsn}$ has very high formation energy throughout the band gap, and because oxygen contamination usually contributes electrons in nitrides. To explain the unusual ZTN material properties, we developed an approach to go beyond the conventional defect model by considering the additional effects of non-equilibrium

synthesis, off-stoichiometry, disorder, and (intentional or unintentional) incorporation of impurities, thereby capturing the physics of non-ideal complex mixed-ion semiconductor materials. ${ }^{13}$ The ZTN calculations results (Fig.1) show that the net doping is a non-monotononic function of the $\mathrm{Zn}$ and $\mathrm{O}$ content, which has been considered as anomalous/unusual in the past. The non-monotonic behavior is mainly due to the composition induced changes in the electronic structure, namely change in the band position and the resulting change in defect formation enthalpies at high $\mathrm{Zn}$ and $\mathrm{O}$ content. This mechanism allows the reduction of the free carrier 
density in highly off-stoichiometric Zn-rich samples, particularly when grown with activated $\mathrm{N}$ sources.

Beside the cation stoichiometry control of the doping, we showed that annealing $\mathrm{Zn}$-rich $\mathrm{ZnSnN}_{2}$ grown with added hydrogen reduces its free electron density by two orders of magnitude, down to $4 \times 10^{16} \mathrm{~cm}^{-3}$. As shown in Fig. 2, zinc-rich $\mathrm{Zn}_{1+x} \mathrm{Sn}_{1-\mathrm{x}} \mathrm{N}_{2}(\mathrm{ZTN})$ has electron concentration of $2 \times 10^{18} \mathrm{~cm}^{-3}$. The electron density of ZTN was reduced down to $2 \times 10^{17} \mathrm{~cm}^{-3}$, either upon annealing or as a result of growth in activated forming gas atmosphere. Most importantly, for ZTN films grown in forming gas and then annealed, the electron density decreased down to $4 \mathrm{x}$ $10^{16} \mathrm{~cm}^{-3}$, suitable for formation of rectifying $\mathrm{p}-\mathrm{n}$ junctions that can be used for solar cell application. ${ }^{14}$ This doping is a factor of 100 lower compared to asdeposited $\mathrm{N}_{2}$-grown films, and a factor of 10,000 compared to what is typically reported in literature. This experimental observation can be explained by

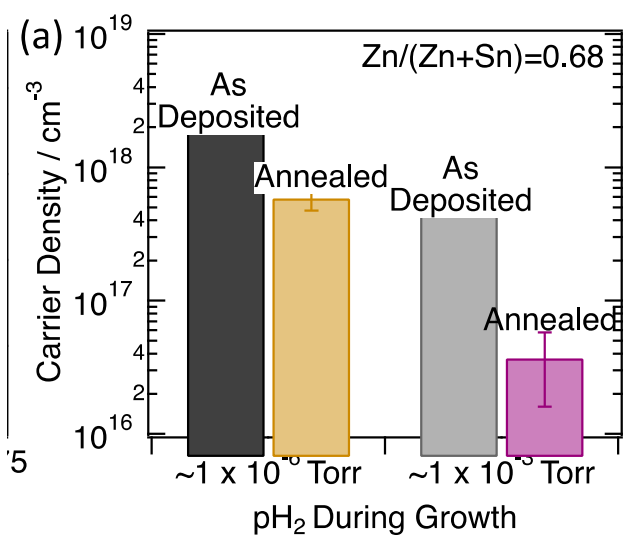

Fig.2 Carrier density as a function of hydrogen available during growth and labeled with post-growth treatment hydrogen passivation of acceptors in $\mathrm{Zn}_{1+} \mathrm{Sn}_{1-\mathrm{x}} \mathrm{N}_{2}$ during growth, lowering the driving force for unintentional donor formation, followed by selective hydrogen removal by annealing. These results indicate that the doping control principles used in $\mathrm{GaN}$ can be translated to $\mathrm{ZnSnN}_{2}$, suggesting that other strategies used in binary III-Vs can be applied to accelerate the development of ternary II-IV-N 2 materials studied in this project.

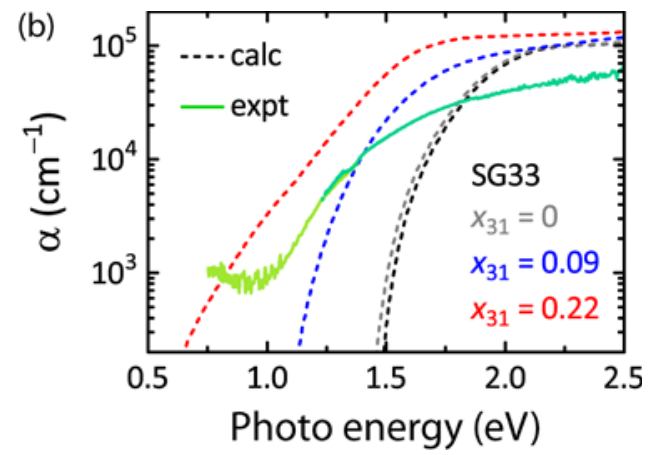

Fig.3 Experimental absorption spectrum in $\mathrm{Zn}$-rich $\mathrm{ZnSnN}_{2}$ in comparison with calculated absorption spectrum for $\mathrm{ZnSnN}_{2}$ in the fully ordered (SG 33) and partially disordered structure
In multinary compound semiconductors like $\mathrm{ZnSnN}_{2}$, cation disorder can decisively alter the optoelectronic properties and impact potential solar cell applications. In the ground state structure of $\mathrm{ZnSnN}_{2}$, every $\mathrm{N}$ anion is coordinated by $2 \mathrm{Zn}$ and 2 Sn cations, forming an ordered network tetrahedral motifs that locally observe the octet rule. Using a motif-based model Hamiltonian, we performed Monte-Carlo simulations that provide atomistic representations of $\mathrm{ZnSnN}_{2}$ with varying degrees of cation disorder. Subsequent electronic structure calculations were used to describe the evolution of band gaps, optical properties and carrier localization effects as function of the disorder. ${ }^{15} \mathrm{We}$ find that octet-rule conserving disorder is practically impossible to avoid, but perfectly benign with hardly any effects on the electronic structure. In contrast, a fully random cation distribution would be very detrimental, but fortunately it is energetically highly unfavorable. The degree of disorder that can realistically be expected for non-equilibrium thin-film deposition (10 - 20\% concentration of non-equilibrium motifs) leads to a moderate band gap reduction and small carrier localization effects. Comparing these results of theoretical simulations with experimental samples grown by 
sputtering and characterized by synchrotron x-ray diffraction patterns and by the optical absorption spectra (Fig. 3), we indeed find evidence of a certain degree (10-20\%) of octet-rule violating cation disorder. This study demonstrates that the optoelectronic properties of $\mathrm{ZnSnN}_{2}$ are affected by the local coordination environments, and that the observed degree of cation disorder is likely to be acceptable for the solar cell absorber applications of this material. In addition to optoelectronic properties and doping control, good electronic structure properties are required from solar cell absorber materials. Thus, we performed a detailed investigation into the structural and electronic properties of low carrier density, zincrich $\mathrm{ZTN}$ films with $\mathrm{Zn} /(\mathrm{Zn}+\mathrm{Sn})=0.67$, by a combination of theory and experiment. ${ }^{16}$ Using high resolution XRD measurements and simulated MonteCarlo structural models, it was determined that zincrich $\mathrm{ZTN}$ is stabilized by the presence of oxygen, thus forming an alloy between $\mathrm{ZnSnN}_{2}$ and $\mathrm{ZnO}$. Calculated defect formation energies demonstrated that formation of electronically benign $\mathrm{ZnSn}_{\mathrm{Sn}}+2 \mathrm{O}_{\mathrm{N}}$ complexes were the atomistic mechanism behind

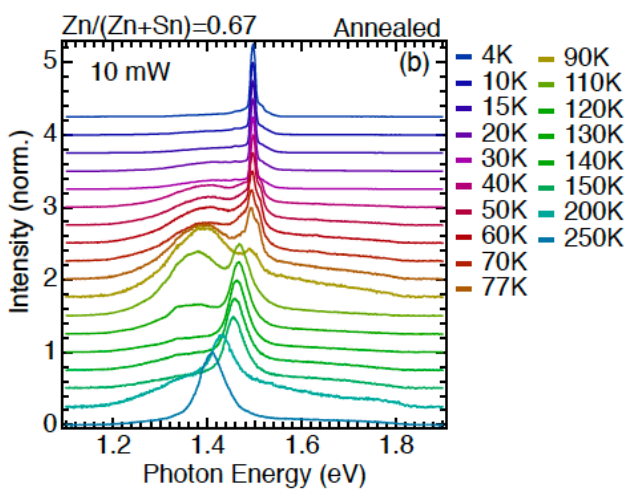

Fig.4 Temperature-dependent PL of the annealed, zinc-rich sample with $\mathrm{Zn} /(\mathrm{Zn}+\mathrm{Sn})=0.67$ oxygen-stabilization of the zinc-rich structure. Low temperature, temperature-dependent, and power-dependent photoluminescence (PL) measurements identified a bound exciton transition in annealed ZTN films (Fig. 4), and these data allowed the bandgap in this material to be estimated at $1.54 \mathrm{eV}$. Observation of the exciton luminescence in polycrystalline thin film samples was explained by the formation of neutral defect complexes upon annealing, resulting in improved electronic quality of the material. Ultimately, the results of this work suggest that ZTN material with both low carrier density and good electronic structure properties can be achieved through a combination of zinc-rich growth, beneficial oxygen incorporation, and post-growth annealing.

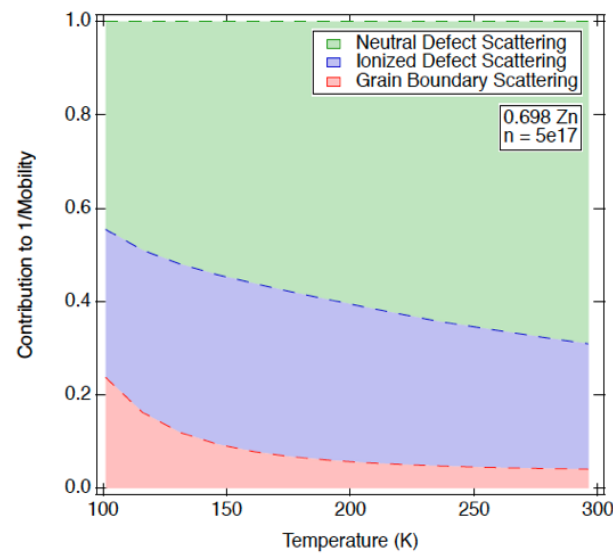

Fig.5 Contribution of different possible scattering mechanisms to the inverse electron mobility vs. measurement temperature
To get further insight into electronic structure and charge carrier transport properties in $\mathrm{ZnSnN}_{2}$, we studied this material experimentally using temperaturedependent Hall effect measurements. ${ }^{17}$ The results of the carrier concentration and mobility measurement were modeled using a combination of three scattering mechanisms, namely neutral defect scattering, ionized defect scattering and grain boundary scattering (Fig.5). The results of these research efforts indicate that at PV-relevant conditions (Room-Temperature measurement on Zn-rich samples), the electron mobility is limited by scattering on neutral defects. Combined with the results of the first principle calculations described above, the most likely microscopic origin of this neutral defect scattering is the $\mathrm{ZnSn}+2 \mathrm{ON}_{\mathrm{N}}$ defect complex. Another conclusion from the experimental measuring and modeling is that the ZTN samples can be described highly compensated semiconductors, with electron density 
being orders of magnitude lower than the dopant densities. These results are consistent with the composition estimates obtained from the combination of XRF, SIMS and RBS measurements, which show that the zinc and oxygen concentration are proportional to each other at PV-relevant Zn-rich composition range with low carrier density.

While carrier concentration of ZTN has been reduced to values suitable for device implementation, other properties such as ionization potential, electron affinity and work function were not known. We used Kelvin probe and Photoemission spectroscopy measurements to determine the ionization potential $(5.6 \mathrm{eV})$, electron affinity $(4.1 \mathrm{eV})$ and work function $(4.4 \mathrm{eV})$ for ZTN thin film samples with $\mathrm{Zn} /(\mathrm{Zn}+\mathrm{Sn})=0.56 .^{18}$ These values would imply that $\mathrm{n}$ type ZTN forms a cliff-type valence band offset with $\mathrm{NiO}$ and $\mathrm{CuCrO}_{2}$ p-type contacts. Further, using both experimental and theoretical results, we built a device model to simulate the performance of a $\mathrm{ZTN} / \mathrm{Mg}: \mathrm{CuCrO}_{2}$ solar cell, showing a potential efficiency of $23 \%$ in the limit of no defects present. The effect of the position of the band edges of the p-type junction partner was assessed in the presence of band tails and defect states (Fig. 6). It was

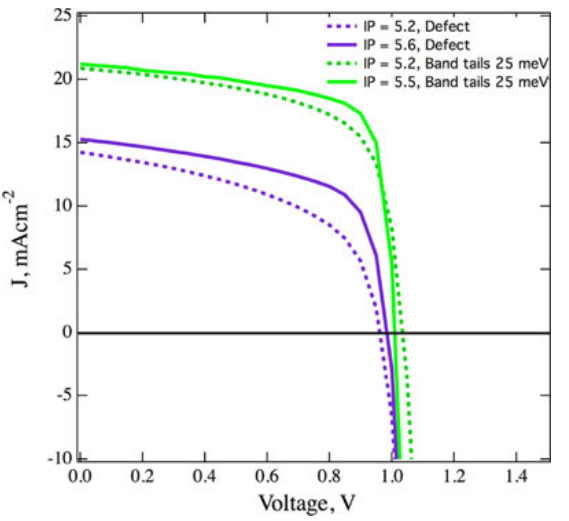

Fig. 6. Simulated JV curves of the $\mathrm{ZTN} / \mathrm{Mg}: \mathrm{CuCrO}_{2}$ heterojunction as a function of increasing IP of $\mathrm{Mg}: \mathrm{CuCrO}_{2}$ found that for this n-type ZTN absorber with relatively low hole mobility and with the aforementioned imperfections, the spike band offset is more detrimental than the cliff band offset, in contrast to solar cells with CdTe or CIGS absorbers. Through this modeling study, we determined the major bottlenecks for the development of ZTN-based solar cell and identified avenues to mitigate them.

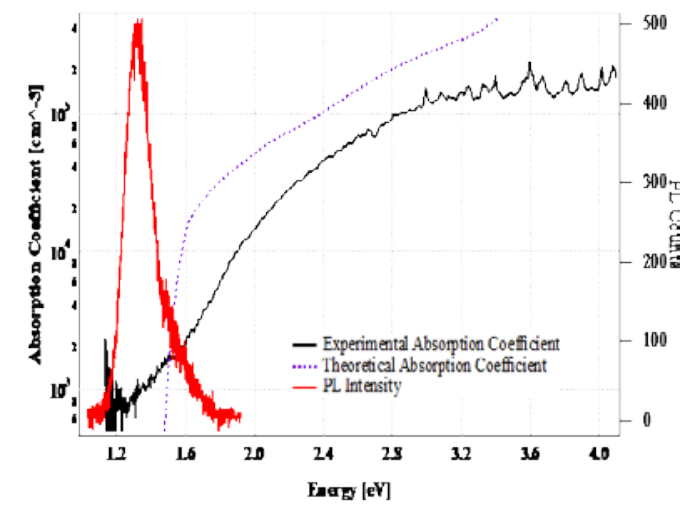

Fig. 7. Optical properties of $\mathrm{Mg}_{3} \mathrm{SbN}$

Besides the mainstream work on $\mathrm{ZnSnN}_{2}$, in this project we evaluated several other new absorbers, down-selected them using theoretical methods, and synthesized some of them. For example, a highthroughput experimental investigation of the computationally predicted $\mathrm{Mg}-\mathrm{Sb}-\mathrm{N}$ ternary system was carried out. ${ }^{19}$ The Mg-Sb-N ternary system was predicted to have three ternary materials, including $\mathrm{Mg}_{3} \mathrm{SbN}$ anti-perovskite with promising PV absorber properties, and previously unreported $\mathrm{Mg}_{2} \mathrm{SbN}_{3}$ with wurtzite-like structure. In particular, for the $\mathrm{Mg}_{3} \mathrm{SbN}$, the effective masses of both electrons and holes are calculated to be $<1 \mathrm{~m}_{0}$ and the relative dielectric constant is 27 , which the band gap is slightly indirect $(1.1 \mathrm{eV})$ and absorption onset is $0.2 \mathrm{eV}$ higher in energy (Fig. 7). The synthesis was performed using radio-frequency magnetron co-sputtering of $\mathrm{Mg}$ and $\mathrm{Sb}$ in $\mathrm{N}$ plasma, and the synthesis phase map has been created. A crystalline form of wurtzite-like $\mathrm{Mg}_{2} \mathrm{SbN}_{3}$ has been synthesized for the first time, consistent in structure with the first principles theory prediction. Similarly, $\mathrm{Mg}_{3} \mathrm{SbN}$ anti-perovskite has been synthesized in thin film form for the first time, facilitating a range of new metrology of this material. Optoelectronic characterization was carried out across this ternary system, confirming the $1.4 \mathrm{eV}$ optical 
absorption onset for $\mathrm{Mg}_{3} \mathrm{SbN}$, and room-temperature photoluminescence (Fig.7). These experimental results support the promise of $\mathrm{Mg}_{3} \mathrm{SbN}$ anti-perovskite as a photovoltaic absorber material.

\section{Conclusions}

We theoretically explained that the carrier density in $\mathrm{ZnSnN}_{2}$ decreases to $10^{17} \mathrm{~cm}^{-3}$ with increasing $\mathrm{Zn}$ and $\mathrm{O}$ content due to formation of defect complexes and modification of the material electronic structure. ${ }^{13}$ Further, we experimentally showed that annealing $\mathrm{Zn}_{1+\mathrm{x}} \mathrm{Sn}_{1-\mathrm{x}} \mathrm{N}_{2}$ grown with added hydrogen reduces its free electron density by orders of magnitude, down to 4 $\times 10^{16} \mathrm{~cm}^{-3}$. ${ }^{14}$ These carrier densities are low enough for formation of rectifying heterojunctions necessary for solar cell fabrication, according to modeling. ${ }^{18}$

We also calculated that octet-rule conserving disorder in $\mathrm{ZnSnN}_{2}$ is practically impossible to avoid but has hardly any effects on the electronic structure. ${ }^{15}$ These theoretical results were supported by experimental measurements of near band edge photoluminescence in the annealed material. ${ }^{16}$ Finally, we experimentally determine the value of ionization potential, electron affinity, and work function for $\mathrm{Zn}_{1+\mathrm{x}} \mathrm{Sn}_{1-\mathrm{x}} \mathrm{N}_{2}$ (ZTN) thin film samples. ${ }^{17}$

In addition to work on $\mathrm{ZnSnN}_{2}$, we also discovered a new wurtzite-like $\mathrm{Mg}_{2} \mathrm{SbN}_{3}$ material in $\mathrm{Mg}-\mathrm{Sb}-\mathrm{N}$ system and reported for the first time on optoelectronic properties of $\mathrm{Mg}_{3} \mathrm{SbN}$ antiperovskite. ${ }^{19}$ All these results were summarized in many peer review publications (see complete list below). We also published a few review papers on nitrides and emerging PV absorbers in FY16-18 project, ${ }^{6,12}$ and finalized publications from the previous FY13-15 project period (also listed below). ${ }^{20,21,22}$

\section{Budget and Schedule}

The total budget of the project is $\$ 1,660,000$ over the three years, with $100 \%$ federal share. The project consisted of three budget periods, one year each starting FY16. There were not significant schedule or cost modifications during the cost of the project.

\section{Path Forward}

Plans for future research and development include collaboration with industrial partners, and work funded by other parts of DOE. The industrial collaborations would use the rapid development approaches of this project to other solar cell technologies, outside of absorber layer. The work with other part of DOE would be on applications unrelated to solar photovoltaic technologies, where new materials challenges are present. 


\section{Publications Resulting from This Work}

The publication listed from the FY16-18 work period are listed below:

A. N. Fioretti, A. Stokes, M. R. Young, B. Gorman, E. S. Toberer, A. C. Tamboli, and A. Zakutayev, Effects of Hydrogen on Acceptor Activation in Ternary Nitride Semiconductors, Advanced Electronic Materials, 3, 1600544 (2017) - highlighted on journal front cover

S. Lany, A. N. Fioretti, P. P. Zawadzki, L. T. Schelhas, E. S. Toberer, A. Zakutayev, and A. C. Tamboli, Monte Carlo simulations of disorder in $\mathrm{ZnSnN}_{2}$ and the effects on the electronic structure, Physical Review Materials 1, 035401 (2017)

E. Arca, A. Fioretti, S. Lany, A. C. Tamboli, G. Teeter, C. Melamed, J. Pan, K. N. Wood, E. Toberer, and A. Zakutayev. "Band Edge Positions and Their Impact on the Simulated Device Performance of $\mathrm{ZnSnN}_{2}$-Based Solar Cells." Invited Article - IEEE Journal of Photovoltaics 8, $110(2018)$

Fioretti, A.N., Pan, J., Ortiz, B.R., Melamed, C.L., Dippo, P.C., Schelhas, L.T., Perkins, J.D., Kuciauskas, D., Lany, S., Zakutayev, A. Toberer, E.S., Tamboli, A.C., Exciton photoluminescence and benign defect complex formation in zinc tin nitride, Materials Horizons 5, 823 (2018) - highlighted on journal inside front cover

A. Zakutayev, Brief review of emerging photovoltaic absorbers, Current Opinion in Green and Sustainable Chemistry, 4, 8, (2017)

AD Martinez, AN Fioretti, ES Toberer, AC Tamboli et al Synthesis, structure, and optoelectronic properties of II-IV-V 2 Journal of Materials Chemistry A 5 (23), 11418-11435 (2017)

J. Pan, J. Cordell, G. J. Tucker, A. Tamboli, A. Zakutayev, S. Lany, Interplay between composition, electronic structure, disorder, and doping due to dual sublattice mixing in nonequilibrium synthesis of $\mathrm{ZnSnN2:O}$, Advanced Materials, in press

D. Hamilton, E. Arca, J. Pan, S. Siol, M. Young, S. Lany, A. Zakutayev, Electron scattering mechanisms in zinc tin nitride, submitted

Publications from FY13-15 work period, that appeared during FY16-18 work period, and were not reported before, are listed next:

de Souza Lucas, F.W. and Zakutayev, A. Research Update: Emerging chalcostibite absorbers for thin-film solar cells, APL Materials, 6084501 (2018)

K. Heinselman, J. Perkins, S. Lany, A. Zakutayev "New PV absorber materials in Mg-Sb-N system", in preparation

Birkett, M., Savory, C.N., Rajpalke, M.K., Linhart, W.M., Whittles, T.J., Gibbon, J.T., Welch, A.W., Mitrovic, I.Z., Zakutayev, A., Scanlon, D.O. and Veal, T.D..Band gap temperaturedependence and exciton-like state in copper antimony sulphide, CuSbS2, APL Materials, 6, 084904 (2018) 
T. J. Whittles, T. D. Veal, C. N. Savory, A. W. Welch, F. W. de Souza Lucas, J. T. Gibbon, M. Birkett, R. J. Potter, D. O. Scanlon, A. Zakutayev, and V. R. Dhanak, Core Levels, Band Alignments, and Valence-Band States in CuSbS2 for Solar Cell Applications, ACS Appl. Mater. Interfaces, 9, 41916 (2017)

F. W. de Souza Lucas, H. Peng, S. Johnston, P. C. Dippo, S. Lany, L. H. Mascaro, A. Zakutayev, Characterization of defects in copper antimony disulfide, Journal of Materials Chemistry A 5, 21986, (2017) 


\section{References}

${ }^{1}$ S. Lany, T. Gershon and A. Zakutayev, Advanced materials for solar energy conversion, in "Roadmap on optical energy conversion", Journal of Optics, 18, 073004 (2016)

2 J. Andrade-Arvizu, M. Courel-Piedrahita, SnS-based thin film solar cells: Perspectives over the last 25 years, Journal of Materials Science: Materials in Electronics 26.7 (2015): 4541-4556.

${ }^{3}$ K. Zeng, D.-J. Xue, J. Tang, Antimony selenide thin-film solar cells, Semicond. Sci. Technol. $31(2016) 63001$.

${ }^{4}$ L. L Baranowski, P. Zawadzki, S. Lany, E.S. Toberer and A.Zakutayev, A review of defects and disorder in multinary tetrahedrally bonded semiconductors, Semicond. Sci. Technol. 31 123004 (2016)

${ }^{5}$ de Souza Lucas, F.W. and Zakutayev, A., Research Update: Emerging chalcostibite absorbers for thin-film solar cells., APL Materials, 6084501 (2018)

${ }^{6}$ Andriy Zakutayev, Brief review of emerging photovoltaicabsorber materials, Current Opinion in Green and Sustainable Chemistry, 4, 8, (2017)

${ }^{7}$ M.C. Beard, Multiple exciton generation in semiconductor quantum dots, J. Phys. Chem. Lett. 2 (2011) 1282-1288

${ }^{8}$ D. König, K. Casalenuovo, Y. Takeda, G. Conibeer, J.F. Guillemoles, R. Patterson, L.M. Huang, M.A. Green, Hot carrier solar cells: Principles, materials and design, Phys. E LowDimensional Syst. Nanostructures. 42 (2010) 2862-2866.

${ }^{9}$ K.T. Butler, J.M. Frost, A. Walsh, Ferroelectric materials for solar energy conversion: Photoferroics revisited, Energy Environ. Sci. 8 (2015) 838-848.

${ }^{10}$ S. Rühle, A.Y. Anderson, H.-N. Barad, B. Kupfer, Y. Bouhadana, E. Rosh-Hodesh, A. Zaban, All-oxide photovoltaics, J. Phys. Chem. Lett. 3 (2012) 3755-3764.

11 A. Zakutayev, Design of nitride semiconductors for solar energy conversion, Journal of Materials Chemistry A 4.18 (2016): 6742-6754.

12 AD Martinez, AN Fioretti, ES Toberer, AC Tamboli et al Synthesis, structure, and optoelectronic properties of II-IV-V 2 Journal of Materials Chemistry A 5 (23), 11418-11435 (2017)

${ }^{13}$ J. Pan, J. Cordell, G. J. Tucker, A. Tamboli, A. Zakutayev, S. Lany, Interplay between composition, electronic structure, disorder, and doping due to dual sublattice mixing in nonequilibrium synthesis of $\mathrm{ZnSnN2:O}$, Advanced Materials, in press 
14 A. N. Fioretti, A. Stokes, M. R. Young, B. Gorman, E. S. Toberer, A. C. Tamboli, and A. Zakutayev, Effects of Hydrogen on Acceptor Activation in Ternary Nitride Semiconductors, Advanced Electronic Materials, 3, 1600544 (2017)

${ }^{15}$ S. Lany, A. N. Fioretti, P. P. Zawadzki, L. T. Schelhas, E. S. Toberer, A. Zakutayev, and A. C. Tamboli, Monte Carlo simulations of disorder in $\mathrm{ZnSnN}_{2}$ and the effects on the electronic structure, Physical Review Materials 1, 035401 (2017)

${ }^{16}$ Fioretti, A.N., Pan, J., Ortiz, B.R., Melamed, C.L., Dippo, P.C., Schelhas, L.T., Perkins, J.D., Kuciauskas, D., Lany, S., Zakutayev, A. Toberer, E.S., Tamboli, A.C., Exciton photoluminescence and benign defect complex formation in zinc tin nitride, Materials Horizons $5,823(2018)$

17 D. Hamilton, E. Arca, J. Pan, S. Siol, M. Young, S. Lany, A. Zakutayev, Electron scattering mechanisms in zinc tin nitride, submitted

${ }^{18}$ E. Arca, A. Fioretti, S. Lany, A. C. Tamboli, G. Teeter, C. Melamed, J. Pan, K. N. Wood, E. Toberer, and A. Zakutayev. "Band Edge Positions and Their Impact on the Simulated Device Performance of $\mathrm{ZnSnN}_{2}$-Based Solar Cells." Invited Article - IEEE Journal of Photovoltaics 8, $110(2018)$

${ }^{19}$ K. Heinselman, J. Perkins, S. Lany, A. Zakutayev "New PV absorber materials in Mg-Sb-N system", in preparation

${ }^{20}$ Birkett, M., Savory, C.N., Rajpalke, M.K., Linhart, W.M., Whittles, T.J., Gibbon, J.T., Welch, A.W., Mitrovic, I.Z., Zakutayev, A., Scanlon, D.O. and Veal, T.D..Band gap temperaturedependence and exciton-like state in copper antimony sulphide, CuSbS2, APL Materials, 6, 084904 (2018)

21 T. J. Whittles, T. D. Veal, C. N. Savory, A. W. Welch, F. W. de Souza Lucas, J. T. Gibbon, M. Birkett, R. J. Potter, D. O. Scanlon, A. Zakutayev, and V. R. Dhanak, Core Levels, Band Alignments, and Valence-Band States in CuSbS2 for Solar Cell Applications, ACS Appl. Mater. Interfaces, 9, $41916(2017)$

${ }^{22}$ F. W. de Souza Lucas, H. Peng, S. Johnston, P. C. Dippo, S. Lany, L. H. Mascaro, A. Zakutayev, Characterization of defects in copper antimony disulfide, Journal of Materials Chemistry A 5, 21986, (2017) 